\title{
The BIOMASS mission - An ESA Earth Explorer candidate to measure the BIOMASS of the earth's forests
}

Scipal, K.; Arcioni, M.; Chave, J.; Dall, Jørgen; Fois, F.; LeToan, T.; Lin, C-C; Papathanassiou, K.; Quegan, S.; Rocca, F.

Total number of authors:

14

Published in:

IEEE International Geoscience and Remote Sensing Symposium

Link to article, DOI:

10.1109/IGARSS.2010.5648979

Publication date:

2010

Document Version

Publisher's PDF, also known as Version of record

Link back to DTU Orbit

Citation $(A P A)$ :

Scipal, K., Arcioni, M., Chave, J., Dall, J., Fois, F., LeToan, T., Lin, C-C., Papathanassiou, K., Quegan, S., Rocca, F., Saatchi, S., Shugart, H., Ulander, L., \& Williams, M. (2010). The BIOMASS mission - An ESA' Earth Explorer candidate to measure the BIOMASS of the earth's forests. IEEE International Geoscience and Remote Sensing Symposium, 52-55. https://doi.org/10.1109/IGARSS.2010.5648979

\section{General rights}

Copyright and moral rights for the publications made accessible in the public portal are retained by the authors and/or other copyright owners and it is a condition of accessing publications that users recognise and abide by the legal requirements associated with these rights.

- Users may download and print one copy of any publication from the public portal for the purpose of private study or research.

- You may not further distribute the material or use it for any profit-making activity or commercial gain

- You may freely distribute the URL identifying the publication in the public portal 


\title{
THE BIOMASS MISSION - AN ESA EARTH EXPLORER CANDIDATE TO MEASURE THE BIOMASS OF THE EARTH'S FORESTS
}

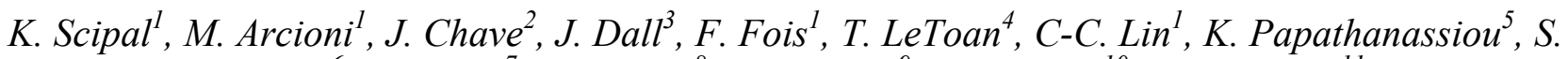

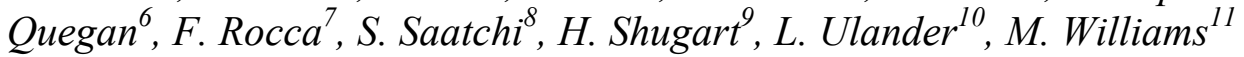 \\ ${ }^{1}$ European Space Agency, Nordwijk, the Netherlands \\ ${ }^{2}$ Centre National de la Recherche Scientifique, Toulouse, France \\ ${ }^{3}$ Technical University of Denmark, Kongens Lyngby, Denmark \\ ${ }^{4}$ Centre d'Etudes Spatiales de la Biosphère, Toulouse, France \\ ${ }^{5}$ German Aerospace Center, Wessling, Germany \\ ${ }^{6}$ University of Sheffield, Sheffield, UK \\ ${ }^{7}$ Politecnico di Milano, Milan, Italy \\ ${ }^{8}$ Jet Propulsion Laboratory, Pasadena, USA \\ ${ }^{9}$ The University of Virginia, Charlottesville, USA \\ ${ }^{10}$ Swedish Defence Research Agency, Linkoping, Sweden \\ ${ }^{11}$ University of Edinburgh, Edinburgh, UK
}

\begin{abstract}
The European Space Agency (ESA) released a Call for Proposals for the next Earth Explorer Core Mission in March 2005, with the aim to select the $7^{\text {th }}$ Earth Explorer (EE-7) mission for launch in the next decade. Twentyfour proposals were received and subject to scientific and technical assessment. Six candidate missions were selected and further investigated in the preliminary feasibility studies (Phase 0 ). One of these missions is BIOMASS, which has recently been selected to proceed to Phase-A. BIOMASS is a response to the urgent need for greatly improved mapping of global biomass and the lack of any current space systems capable of addressing this need.
\end{abstract}

\section{Index Terms - Biomass, PolInSAR, P-band}

\section{INTRODUCTION}

Earth Explorer missions focus on the science and research elements of ESA's Living Planet Programme. Encompassing a new approach to observing the Earth from space, Earth Explorers are developed in direct response to challenges identified by the scientific community.

The BIOMASS mission is a response to the urgent need for greatly improved mapping of global biomass and the lack of any current space systems capable of addressing this need. The objective of BIOMASS is to map the full range of the world's above-ground biomass with accuracy and spatial resolution compatible with the needs of national scale inventory and carbon flux calculations, and shall map changes in forest biomass [1].

The mission was proposed to the European Space Agency for the third cycle of Earth Explorer Core missions. After successfully going through an Assessment Study (Phase 0) it was selected for Feasibility Study (Phase A) in March 2009 together with two other candidate missions, $\mathrm{CoReH}_{2} \mathrm{O}$ and PREMIER. At the end of Phase A one of the three candidate missions will be selected for implementation.

\section{MISSION OBJECTIVES}

\subsection{Scientific background}

At present, the status, dynamics and evolution of the terrestrial biosphere are the least understood and the most uncertain elements in the global carbon cycle, which is deeply imbedded in the functioning of the Earth and climate systems. There are very large uncertainties in the distribution of carbon stocks and carbon exchange, in the estimates of carbon emissions due to land use change, and in the uptake of carbon due to forest re-growth. Forest biomass is the main repository of vegetation carbon and hence is a crucial quantity needed to reduce these uncertainties. Both its spatial distribution and its change with time are critical for improved knowledge of the terrestrial component of the carbon cycle.

\subsection{Observation Requirements}


To address this uncertainty BIOMASS needs to provide information on: (1) Forest areas and above ground forest biomass (dry weight of woody matter + leaves) expressed in tons/ha at 100-200 m spatial resolution, with $<20 \%$ accuracy; (2) Forest Height (meters above ground) at 100$200 \mathrm{~m}$ spatial resolution, with $<20-30 \%$ accuracy; and (3) Disturbance and forest recovery with time at 50/200 m spatial resolution (major/partial disturbances) with $90 \%$ classification accuracy. This information will be available on a global scale twice per year.

To achieve these objectives the BIOMASS mission will be implemented as a P-band SAR in side-looking geometry with full polarimetric and interferometric capabilities. Such mission will seize the new opportunity from the allocation of a P-band frequency band for remote sensing by the International Telecommunications Union in 2003 .

Many airborne observations in tropical, temperate and boreal forests have demonstrated that P-band SAR has unique capabilities for measuring the world-wide range of forest biomass. It can achieve this by combining complementary techniques: forest biomass is retrieved directly from multi-polarised backscatter measurements, with decreasing sensitivity as biomass increases, while forest height is derived from Pol-InSaR, with increasing sensitivity as height and biomass increase.

This will allow to provide not only information on the global biomass distribution but it will be the first opportunity of exploring the Earth's surface at the P-Band wavelength with anticipated applications in subsurface geomorphology, ice structure and interferometric ice flow measurements and forest inundation mapping.

\section{MISSION CONCEPTS}

The BIOMASS payload consists of a fully polarimetric system operated at a centre frequency of $435 \mathrm{MHz}$ (Pband) with a bandwidth of $6 \mathrm{MHz}$. Measurements will be taken at incidence angles ranging from 23 to 31 degrees. The Noise Equivalent Sigma Zero will be better than -27 $\mathrm{dB}$. To enable measurements at a scale comparable to that of deforestation and forest disturbance (i.e. around 1 ha), it is envisaged that BIOMASS will provide level-1 products with around $50 \mathrm{~m} \times 50 \mathrm{~m}$ resolution at 4 looks, so around 16 looks at a scale of 1 ha. The satellite shall fly in a sun-synchronous dawn-dusk orbit to minimise ionospheric disturbances with a controlled drift to meet the revisit requirement for forest height recovery using Pol-InSAR techniques. The revisit time will be between 25-45 days to maintain high temporal coherence. In this setup the mission will achieve coverage of the earth's forests regions at least twice per year. The mission duration is planned for 5 years in order to obtain repeated measurements of the world's forests. At the beginning of the mission a short tomographic phase ( $\sim 2$ months $)$ is foreseen during which measurements with 10-12 spatial baselines and a revisit time of 1-4 days will be collected over selected forest regions.

Three instrument concepts have been developed in the course of the Phase 0 studies together with specific accommodation configurations, as depicted in Figure 1. A more complete description can be found in the BIOMASS Report for Assessment [2].

Concept- $A$ : $27.5 m \times 2.82 m$ antenna

It makes use of the so-called Snapdragon platform concept to achieve a deployed antenna length of $27.5 \mathrm{~m}$. The accommodation of the antenna folded along the launcher central axis limits the maximum aperture elevation height to $2.82 \mathrm{~m}$, allowing a maximum of 5 radiator-rows. The instrument operates in scan-on-receive mode and the large length of the antenna allows reducing the radar PRF.

\section{Concept-B: $20.1 \mathrm{~m} \times 3.26 \mathrm{~m}$ antenna}

It consists of a deployable planar array antenna on a conventional platform concept. The antenna aperture of $20.1 \mathrm{~m} \times 3.26 \mathrm{~m}$ is made of 9 mechanical/electrical panels connected by hinges. The central panel is directly mounted on the face of the payload module oriented towards the Earth, whereas two wings of four panels each are folded and stowed around the perpendicular faces for launch.

\section{Concept-C: Large Deployable Antenna}

It makes use of a Large Deployable Antenna (LDA), of which an Engineering Model was developed with a projected aperture of $12 \mathrm{~m}$ diameter, focal length of $6.3 \mathrm{~m}$ and offset clearance of $3 \mathrm{~m}$. The advantage of the reflector-based concept is its compact stowed dimensions, possibly suitable for accommodation in a small launcher such as VEGA. The feed element is based on honeycombsupported microstrip patches. Two operational modes have been retained for performance evaluation: the ScanSAR mode with the capability to cover in full polarization two sub-swaths of $105 \mathrm{~km}$ in total, with a resolution of $100 \mathrm{~m} \times 100 \mathrm{~m}$ with eight looks; and the Stripmap mode with a swath of $60 \mathrm{~km}$ with a resolution of $50 \mathrm{~m} \times 50 \mathrm{~m}$ with four looks. 


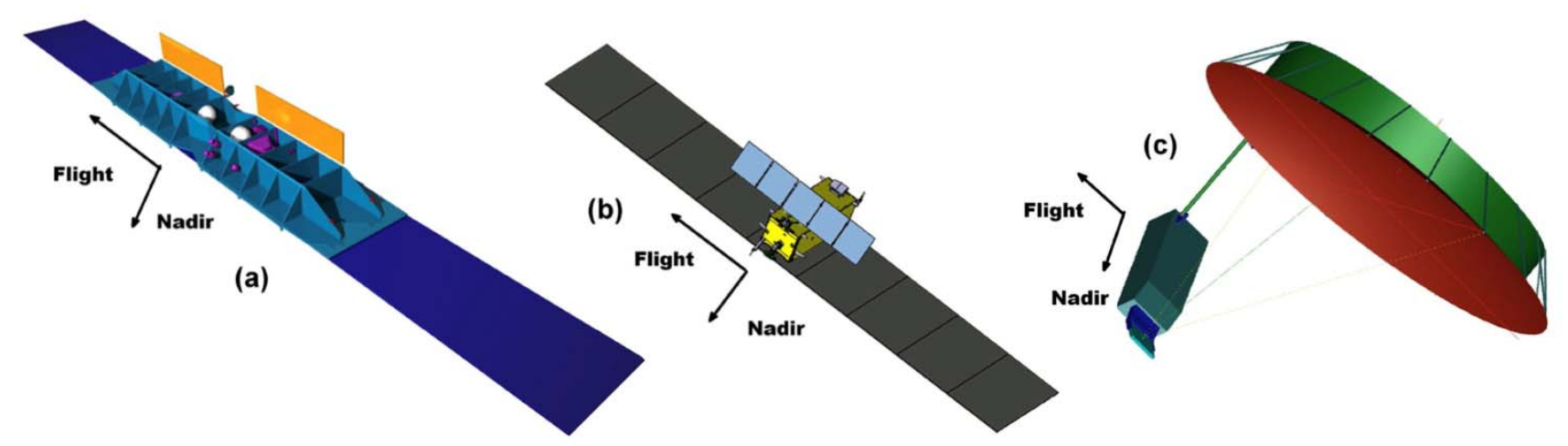

Figure 1. BIOMASS satellite configuration options analyzed during phase 0

\section{SUMMARY OF PHASE-A OBJECTIVES}

Phase A foresees a number of scientific and technological activities to consolidate the mission concept developed in Phase 0 and address open scientific issues. From a system point of view the main challenge in Phase $\mathrm{A}$ is the reduction of the antenna size to make it compatible with the VEGA launcher. Scientifically the activities focus on the development of an end to end system calibration under the presence of ionospheric disturbances and the formulation and evaluation of a global biomass retrieval algorithm.

\subsection{System design}

The phase A studies are currently focusing on reducing the antenna length of concept B from $20.1 \mathrm{~m}$ to $\sim 11 \mathrm{~m}$ by applying the Dual Phase Center Antenna (DPCA) technique combined with the Azimuth Phase Coding (APC) technique. Such antenna would be compatible with the VEGA launcher, which is a major constraint for the BIOMASS mission design, and has the potential to allow a global coverage in 6 months with a 25 days repeat cycle.

DPCA consists of a passive planar phased array made of two antenna halves in along track. The complete antenna is used in transmission, whereas the two halves are used in reception. Under ideal conditions, this allows a reduction of the instrument pulse repetition frequency (PRF) by a factor of two. In literature [3] the reduction of the instrument PRF is used to enable a larger swath-width, whereas in BIOMASS the idea is to keep the swath width and use DPCA to almost halve the antenna length.

The shorter DPCA however requires additional ambiguity suppression in order to meet the required ambiguity ratio of $-20 \mathrm{~dB}$. To this end a novel ambiguity suppression technique, proposed in [4] is investigated. This technique suppresses range ambiguities with an azimuth filter after having applied an azimuth phase modulation to the transmitted pulses and a corresponding demodulation to the received pulses. The technique excels by actually eliminating the ambiguities rather than just defocusing them as most other techniques do, which makes it applicable to distributed targets.

\subsection{Scientific challenges}

The main scientific challenge in Phase A is the formulation of a global biomass retrieval algorithm. Several studies showed the use of intensity data in biomass retrieval, while other studies promoted the derivation of canopy height from Pol-InSAR and the retrieval of information on forest structure from SAR tomography. It is of considerable value that these independent types of information can be provided by the same SAR system and combined in biomass retrieval, as is illustrated in Figure 2 using data from Remningstorp/Sweden. Here the retrieval is based on linear regression of the mean values of intensity, Pol-InSAR height and tomographic Ground to Volume backscatter ratio derived from 10 reference plots of $80 \mathrm{~m} \times 80 \mathrm{~m}$, where accurate in situ biomass measurements are available. The figure shows the comparison between estimated biomass and in situ biomass for inversion of HV intensity data, inversion using $\mathrm{HV}$ and $\mathrm{HH}$ intensity data together with Pol-InSAR height, and inversion using $\mathrm{HV}$ and $\mathrm{HH}$ intensity data, Pol-InSAR height and the Ratio of Ground to Volume backscatter at HV. The RMS error in biomass reduces as more information is added into the inversion, going from $42.3 \mathrm{tha}^{-1}$ when using just HV intensity, to 27.9 $\mathrm{t} \mathrm{ha}^{-1}$ with the addition of $\mathrm{HH}$ and Pol-InSAR height, and to $11.0 \mathrm{t} \mathrm{ha}^{-1}$ when the tomographic HV ground to canopy backscatter ratio is included. 

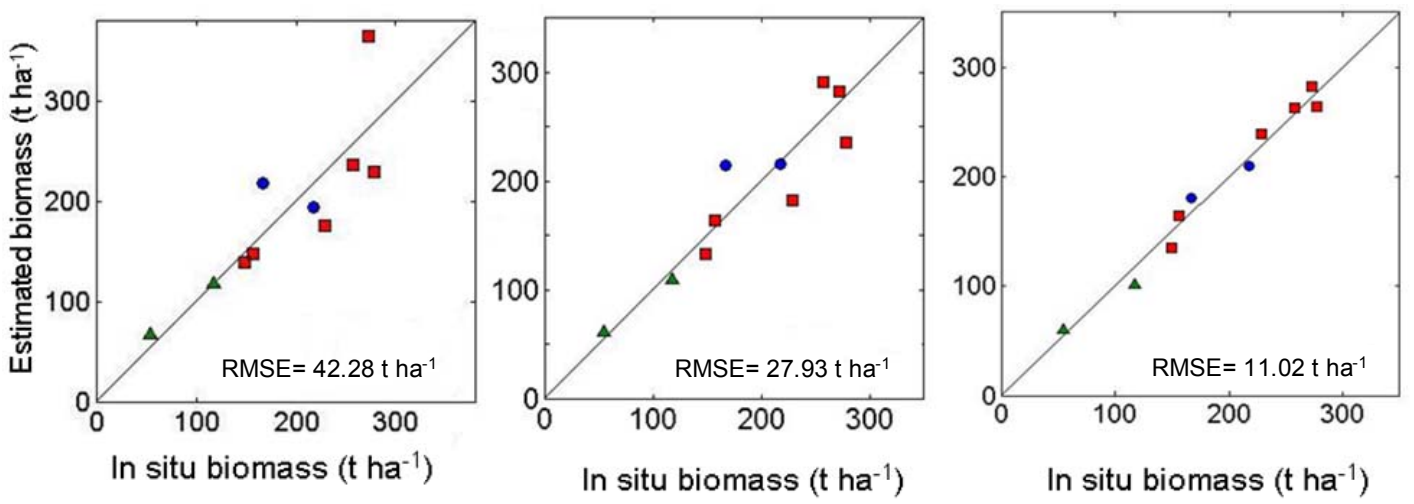

Figure 2. Comparison of estimated and in situ biomass for inversion of HV intensity data (left); inversion using $H V \&$ HH intensity data together with Pol-InSAR height (middle); and inversion using HV \& HH intensity data, Pol-InSAR height and the HV Ground to Volume backscatter ratio (right). Red squares: spruce stands, blue dots: pine stands, and green triangles: birch stands.

The inversion techniques are currently being tested on new airborne P-band datasets acquired to assess two important effects: a) the impact of topography on backscatter intensity and Pol-InSAR, and hence on biomass retrieval; this uses data acquired in 2008 from a boreal forest with strong topography; b) the temporal decorrelation in tropical forests over time-intervals comparable with those for a spaceborne system (20-45 days), using data acquired in French Guiana in 2009. An important aim of this work is to provide better statistical characterisation of the errors in the inversions. These errors are likely to depend on the biomass itself, as well as on issues such as system noise, calibration errors and "geophysical" scatter arising from environmental perturbations of the inversion relation

\section{CONCLUSIONS}

The design of the BIOMASS mission is driven by science needs, and spins together two main observational strands: (1) the long heritage of airborne observations in tropical, temperate and boreal forest that have demonstrated the unique capabilities of P-band multi-polarised SAR for measuring the world-wide range of forest biomass; (2) new developments in recovery of forest height from Pol-InSAR, and, crucially, the resistance of P-band to temporal decorrelation, which makes this frequency uniquely suitable for biomass measurements with a single repeat-pass satellite.
The BIOMASS P-band radar is the only sensor capable of providing the urgently needed global knowledge about biomass.

It also will be a major addition to current efforts to build a global carbon data assimilation system that will harness the capabilities of a range of satellites and in situ data. It is within this context that BIOMASS will find its fullest expression, both gaining from and complementing what can be learnt from other satellite systems, ground data, and carbon cycle models.

\section{REFERENCES}

[1] T. Le Toan, S. Quegan, M. Davidson, H. Balzter, P. Paillou, K. Papathanassiou, S. Plummer, F. Rocca, S. Saatchi, H. Shugart, and L. Ulander, "The BIOMASS Mission: Mapping global forest biomass to better understand the terrestrial carbon cycle," Remote Sensing of Environment, in press, 2010.

[2] ESA, "BIOMASS: Candidate Earth Explorer Core Mission Report for Assessment," 2008, p. 132.

[3] J. Mittermayer and H. Runge, "Conceptual studies for exploiting the TerraSAR-X dual receiving antenna," Proceedings of the IEEE 2003 International Geoscience and Remote Sensing Symposium, 2003.

[4] J. Dall and A. Kusk, "Azimuth Phase Coding for Range Ambiguity Suppression in SAR," Proceedings of the IEEE 2004 International Geoscience and Remote Sensing Symposium, 2004. 